\title{
PROFESIONALISME GURU DALAM MENINGKATKAN PRESTASI SISWA PADA MADRASAH TSANAWIYAH DI KECAMATAN DUAMPANUA KABUPATEN PINRANG
}

\author{
Samonding \\ Kementerian Agama Kab. Pinrang \\ Jalan Bintang No. 8 Kabupaten Pinrang \\ Email: fajrin_muhammad87@yahoo.co.id
}

\begin{abstract}
Abstrak:
Penelitian ini bertujuan; 1) mengetahui tingkat profesionalisme guru pada Madrasah Tsanawiyah di kecamatan Duampanua kabupaten Pinrang. 2) mengetahui tingkat prestasi siswa pada Madrasah Tsanawiyah di kecamatan Duampanua kabupaten Pinrang. 3) mengetahui tingkat profesionalisme guru pengaruhnya terhadap prestasi belajar siswa pada Madrasah Tsanawiyah di Kecamatan Duampanua Kabupaten Pinrang. Penelitian ini bersifat deskriptif kuantitatif dengan jenis penilitian Ex Post Facto. Lokasi penelitian ini adalah Madrasah Tsanawiyah di wilayah Kecamatan Duampanua Kabupaten Pinrang. Populasi dari penelitian ini adalah kepala madrasah, guru, siswa, orang tua, dan unsur lainnya dalam lingkup Madrasah Tsanawiyah se Kecamatan Duampanua Kabupaten Pinrang, dengan sampel $25 \%$ dari jumlah populasi. Metode pengumpulan data yang digunakan adalah; observasi, wawancara, angket, dan dokumentasi. Teknik analisis data adalah persentase kuantitatif. Hasil penelitian menunjukkan profesionalisme guru cukup memadai baik dari aspek kualitas maupun kuantitasnya. Prestasi belajar siswa tergolong dalam kategori tinggi. Pengaruh profesionalisme guru terhadap peningkatan prestasi belajar siswa yang diukur dengan enam aspek masuk dalam kategori tinggi.
\end{abstract}

\begin{abstract}
:
The aim of this study were 1) to find out the level of teachers' professionalism in MTs at Duampanua District, Pinrang Regency, 2) to find out the level of student achievement in MTs at Duampanua disctict, Pinrang Regency. 3) to find out the effect of teachers' professionalism toward student achievement in MTs at Duampanua Distict, Pinrang Regency. This research was descriptive quantitative, with ex post facto design. The location of this research was MTs at Duampanua District, Pinrang Regency. The population of this research was the headmaster, teachers, students, parents, and other elements in all MTs at Duampanua district, Pinrang regency, with a sample of $25 \%$ of the total population. The data collection methods were observation, interviews, questionnaires, and documentation. The technique of data analysis was the quantitative using percentage. The results of the research showed that teacher professionalism was good in both aspects quality and quantity. Student achievement was classified high category. The effect of teachers' professionalism toward the increasing of student achievement measured by the six aspects was in the high category.
\end{abstract}

Kata kunci:

Profesionalisme Guru, Madrasah Tsanawiyah, Prestasi Siswa 
DUNIA pendidikan dalam era globalisasi dewasa ini telah mengalami kemajuan yang cukup pesat, baik pada aspek kuantitas lembaga, peningkatan sarana dan prasarana, pengembangan kurikulum maupun pada berbagai aspek yang terkait didalamnya. Kemajuan tersebut, merupakan hasil yang dicapai dari berbagai usaha yang dilakukan dengan sungguh-sungguh oleh keseluruhan komponen bangsa khususnya yang terkait langsung dengan dunia pendidikan.

Kemajuan yang dialami tersebut, merupakan perwujudan dari usaha pencapaian tujuan pendidikan sebagaimana tertuang dalam Undang-Undang RI No. 20 Tahun 2003 tentang Sistem Pendidikan Nasional (Sisdiknas) bab II Pasal 3 dikatakan, bahwa Pendidikan Nasional berfungsi untuk mengembangkan kemampuan dan membentuk watak serta peradaban bangsa yang bermartabat dalam rangka mencerdaskan kehidupan bangsa, bertujuan untuk berkembangnya potensi peserta didik agar menjadi manusia yang beriman dan bertakwa kepada Tuhan Yang Maha Esa, berakhlak mulia, sehat berilmu, cakap, kreatif, mandiri, dan menjadi warga negara yang demokratis serta bertanggung jawab. ${ }^{1}$

Berdasarkan hal tersebut di atas, maka masalah pokok yang akan dikaji adalah:

1. Bagaimana gambaran tingkat profesionalisme guru pada Madrasah Tsanawiyah di kecamatan Duampanua kabupaten Pinrang?

2. Bagaimana gambaran tingkat prestasi belajar siswa pada Madrasah Tsanawiyah di kecamatan Duampanua kabupaten Pinrang?

3. Bagaimana pengaruh profesionalisme guru terhadap prestasi belajar siswa Madrasah Tsanawiyah di kecamatan Duampanua kabupaten Pinrang?

\section{TINJAUAN TEORETIS}

\section{Kepemimpinan Manajerial Madrasah}

Salah satu faktor yang mampu membuat organisasi pendidikan tetap eksis adalah adanya kompotensi para pemimpin yang dimilikinya. Kompetensi pemimpin yang memadai cenderung meningkatkan produktivitas organisasi, tetapi sebaliknya pemimpin yang kurang memiliki kompetensi cenderung membuat organisasi mandeg atau mundur. Bahkan lebih patal lagi, dapat berakibat pada matinya organisasi. Hal demikian juga berlaku pada Madrasah Tsanwiyah yang ada di kecamatan Duampanua kabupaten Pinrang sebagai bahagian dari ciri kehidupan organisasi yang secara khusus menyelenggarakan pendidikan yang bercirikan Islam.

\section{Profesionalisme Tenaga Pendidik (Guru)}

Peningkatan dan Pengembangan tenaga kependidikan pada Madrasah Tsanawiyah yang ada di kecamatan Duampanua kabupaten Pinrang didasarkan pada kebijaksanaan pengembangan kemampuan profesionalisme ketenagaan sebagai upaya peningkatan mutu dan kualitas pelayanan kependidikan pada Madrasah Tsanawiyah yang ada di kecamatan Duampanua kabupaten Pinrang. Hal ini diorientasikan pada peningkatan keahlian, wawasan, spirit ilmiah serta loyalitas pada tugas yang menjadi beban dan tanggung jawabnya. 
Profesionalisme adalah suatu pandangan yang mengajarkan bahwa setiap pekerjaan harus dilakukan oleh orang yang profesional, yakni orang yang memiliki profesi. ${ }^{2}$ Kata profesi masuk ke dalam kosa kata bahasa Indonesia melalui bahasa Inggris profession atau bahasa Belanda professie. Kedua kata tersebut, berasal dari bahasa latin, yaitu; kata profession yang berarti pengakuan atau pernyataan. ${ }^{3}$

\section{Minat Belajar Siswa}

Minat belajar secara bahasa terdiri dari dua suku kata yaitu; minat dan belajar. Kata minat berarti "kecenderungan hati yang tinggi terhadap sesuatu, gairah atau keinginan". ${ }^{4}$ Sementara kata belajar berarti "berusaha memperoleh kepandaian atau ilmu". ${ }^{5}$ Dari pengertian kata minat dan belajar tersebut dapatlah dirumuskan pengertian minat belajar secara bahasa adalah keinginan hati yang tinggi untuk berusaha memperoleh kepandaian atau ilmu.

\section{Cara-Cara Membangkitkan Minat Belajar Siswa}

H. Suprijanto mengemukakan bahwa langkah-langkah yang dapat ditempuh guru dalam membangkitkan minat belajar siswa meliputi;

a. Guru harus menunjukkan bahwa ia antusias untuk benar mengantarkan anak didik dapat berprestasi pada mata pelajaran yang diajarkan;

b. Siswa hurus diberi kesempatan untuk mengetahui secara jelas materi yang diajarkan malalui jalan pikirannya;

c. Mendorong siswa agar selalu memiliki rasa tertarik yang tinggi pada setiap materi yang diajarkan;

d. Pengetahuan yang diajarkan kepada siswa dalam setiap pertemuan harus dibuat terus berkembang;

e. Setiap pertemuan mengajar siswa dibuat agar selalu berpikir terhadap materi yang diajarkan;

f. Kemajuan belajar siswa terus dilaporkan kepada siswa dalam setiap kegiatan mengajar;

g. Guru harus menunjukkan rasa senang terlihat belajar bersama peserta didik daripada menunjukkan pendapat pribadi;

h. Suasana belajar pada setiap pertemuan harus akrab, gembira, senang, sopan dan demokratis. ${ }^{6}$

\section{Faktor-Faktor yang Mempengaruhi Minat Belajar Siswa}

Menurut Riber yang dikutip Muhibbin Syah bahwa minat tidak termasuk istilah populer dalam psikologi karena ketergantungannya yang banyak pada faktor-faktor lainnya seperti; perhatian, keingin tahuan, motivasi, kebutuhan, dan lain-lainnya. Namun demikian terlepas dari populer atau tidak, minat seperti yang dipahami dan dipakai orang selama ini dapat mempengaruhi keadaan kualitas pencapaian terhadap sesuatu. Misalnya hasil belajar siswa dalam bidang-bidang studi tertentu, dimana seorang siswa yang menaruh minat besar terhadap fiqih akan memusatkan perhatian- 
nya lebih banyak dari pada siswa lainnya, sehingga pemusatan perhatian yang intensif tersebut terhadap materi itulah yang memungkinkan siswa tadi untuk belajar giat dan akhirnya mencapaim prestasi yang diinginkannya. Guru dalam kaitan ini seyogyanya berusaha membangkitkan minat siswa untuk menguasai bidang studi dengan cara yang baik, bermanfaat, dan sesuai dengan harapan yang ingin dicapai. ${ }^{7}$

\section{Tenaga Teknis Administrasi dan Laboran}

Memperhatikan kembali pada pengertian administrasi pendidikan, maka akan ditemukan beberapa bentuk pengertian yang menurut hemat penulis, semua pengertian tersebut pada hakekatnya sama. Inti yang disebutkan berkisar pada beberapa hal sebagaimana yang terdapat dalam "Dictionary of Education" Administrasi pendidikan diartikan dengan:

1. Pengarahan, pengendalian dan pengelolaan semua masalah yang berhubungan urusan-urusan persekolahan, yang meliputi administrasi keuangan, selama aspekaspek kegiatan sekolah memang benar-benar diarahkan untuk mencapai tujuan pendidikan.

2. Pengarahan, pengendalian dan pengelolaan aspek-aspek administrasi sekolah itu terutama secara langsung diarahkan pada proses pengajaran bukan pada aspekaspek lainnya, (seperti; keuangan, guru, siswa, program pengajaran, program kerja, korikuler, metode, alat bantu mengajar dan bimbingan). ${ }^{8}$

\section{Korelasi Profesionalisme Guru dengan Minat dan Prestasi Belajar Siswa}

Guru sebagai tenaga profesional di bidang kependidikan, di samping memahami hal-hal yang bersifat filosofis dan konseptual, juga harus mengetahui dan melaksanakan hal-hal yang bersifat teknis. Hal-hal yang bersifat teknis terutama kegiatan mengelola dan melaksanakan interaksi belajar mengajar. Dalam kegiatan mengelola kelas dan interaksi belajar mengajar, guru paling tidak harus memiliki dua modal dasar, yaitu keterampilan mendesain program dan keterampilan mengkomunikasikan program itu kepada peserta didik.

\section{METODE PENELITIAN}

\section{Lokasi Penelitian}

Lokasi penelitian ini adalah seluruh Madrasah Tsanawiyah yang ada dalam wilayah Kecamatan Duampanua Kabupaten Pinrang yang berjumlah 4 (empat) madrasah.

\section{Populasi dan Sampel}

\section{Populasi}

Populasi dalam penelitian ini adalah; Kepala MTs. se-Kecamatan Duampanua Kabupaten Pinrang sebanyak 4 orang, Guru MTs. se-Kecamatan Duampanua Kabupaten Pinrang sebanyak 66 orang, Siswa sebanyak 348 orang, Orang Tua siswa sebanyak 348 orang, dan unsur lainnya sebanyak 75 orang, dengan jumlah 
keseluruhan 769 orang.

Peta populasi dapat dilihat melalui table 1 sebagai berikut:

Tabel 1. Populasi Penelitian

\begin{tabular}{|c|l|c|}
\hline No. & \multicolumn{1}{|c|}{ KOMPONEN } & JUMLAH \\
\hline 1. & Kepala Sekolah & 4 \\
\hline 2. & Guru & 66 \\
\hline 3. & Siswa & 348 \\
\hline 4. & Orang Tua & 348 \\
\hline 5. & Lainnya & 75 \\
\hline
\end{tabular}

Sampel

Sampel adalah suatu kumpulan obyek penelitian yang hanya dengan mempelajari dan mengamati sebagian dari kumpulan itu. ${ }^{9}$ Sampel dalam penelitian ini sebanyak 85 orang.

\section{Metode Pengumpulan Data}

Instrumen yang digunakan dalam penelitian ini adalah: 1) observasi, 2) wawancara/interview, 3) kuesioner atau angket, dan 4) dokumentasi

\section{Teknik Analisis Data}

Dalam hal pengolahan dan analisis data penelitian, dilakukan dengan mengelompokkan atau mengklasifikasikan data menurut jenis, tujuan dan kepentingan analisis sehingga memudahkan dalam melakukan interpretasi atau dalam menjelaskan berbagai masalah penelitian yang ingin dijawab. Teknik analisis data yang digunakan adalah deskriptif kuantitatif dengan rumus persentase.

\section{HASIL PENELITIAN}

\section{Keadaan Sarana dan Prasarana Madrasah Tsanawiyah di Kecamatan Duampanua}

Membahas tentang lembaga pendidikan, tentunya tidak terlepas dari pembicaraan tentang sarana dan prasarana pendukung yang harus dipenuhi, jika suatu lembaga pendidikan mengharapkan mutu lulusannya lebih baik. Karena itu, dipandang penting untuk mengemukakan beberapa aspek yang terkait dengan sarana dan prasarana yang dimiliki oleh keempat Madrasah Tsanawiyah yang ada di kecamatan Duampanua dan dikemukakan secara beurutan sebagai berikut.
a. Madrasah Tsanawiyah DDI Kaluppang
b. Madrasah Tsanawiyah DDI Kaballangang
c. Madrasah Tsanawiyah DDI Sokang
d. Madrasah Tsanawiyah DDI Pekkabata

\section{Kurikulum Madrasah Tsanawiyah di Kecamatan Duampanua}

Kurikulum dapat diartikan sebagai segala kegiatan dan pengalaman belajar yang direncanakan dan diorganisir agar dapat mencapai tujuan yang telah ditetap- 
kan. Madrasah sebagai lembaga pendidikan dalam menyelesaikan program pendidikannya dalam rangka merumuskan kualifikasi umum yang diharapkan dapat dimiliki oleh anak didik adalah cita-cita luhur agama Islam, yaitu; untuk menjadikan seseorang muslim yang bertaqwa kepada Allah swt., berakhlak mulia serta dapat memahami dan mengamalkan ajaran agamanya.

Program pengajaran yang termuat dalam kurikulum terdiri atas sejumlah mata pelajaran sebagai berikut: 1) Al-Qur'an Hadist, 2) Aqidah Akhlak, 3) Fiqh, 4) Sejarah Kebudayaan Islam, 5) Pendidikan Kewarganegaraan, 6) Bahasa Indonesia, 7) Bahasa Arab, 8) Bahasa Inggris, 9) Matematika, 10) Ilmu Pengetahuan Alam, 11) Ilmu Pengetahuan Sosial, 12) Seni Budaya, 13) Pendidikan Jasmani, Olahraga dan Kesehatan Keterampilan, 14) Mulok, 15) Pengembangan Diri. ${ }^{10}$

\section{Keadaan Guru Berdasarkan Status Kepegawaian}

Kondisi guru pada Madrasah Tsanawiyah di Kecamatan Duampanua yang terdiri atas empat madrasah dilihat dari aspek status kepegawaiannya terdiri atas Pegawai Negeri Sipil, Honorer dan Sukarela. Berdasarkan data dari Kantor Kementerian Agama Kabupaten Pinrang, kondisi guru berdasarkan status kepegawaian dapat dilihat pada tabel berikut:

Tabel 3. Keadaan Guru Madrasah Tsanawiyah di Kecamatan Duampanua Berdasarkan Status Kepegawaian, Jenis Kelamin dan Pendidikan Terakhirnya

\begin{tabular}{|c|c|c|c|c|c|c|c|c|c|c|c|}
\hline \multirow{2}{*}{ No. } & \multirow{2}{*}{ Nama Madrasah } & \multirow{2}{*}{$\begin{array}{l}\text { Status } \\
\text { Pegawai }\end{array}$} & \multicolumn{2}{|c|}{$\begin{array}{c}\text { Jenis } \\
\text { Kelamin }\end{array}$} & \multicolumn{6}{|c|}{ Pendidikan Terakhir } & \multirow{2}{*}{ Jml } \\
\hline & & & $\mathrm{L}$ & $\mathrm{P}$ & SMA & D2 & D3 & D4 & S1 & S2 & \\
\hline \multirow[t]{3}{*}{1.} & $\begin{array}{l}\text { MTs DDI } \\
\text { Kaluppang }\end{array}$ & PNS & - & - & - & - & - & - & - & - & \multirow{3}{*}{17} \\
\hline & & Honorer & 9 & 8 & - & - & - & - & 17 & - & \\
\hline & & Sukarela & - & - & - & - & - & - & - & - & \\
\hline \multirow[t]{3}{*}{2.} & $\begin{array}{l}\text { MTs } \\
\text { Kaballangang }\end{array}$ & PNS & 4 & 1 & - & - & - & - & 5 & - & \multirow{3}{*}{27} \\
\hline & & Honorer & 16 & 6 & - & - & - & - & 22 & - & \\
\hline & & Sukarela & - & - & - & - & - & - & - & - & \\
\hline \multirow[t]{3}{*}{3.} & MTs Sokang & PNS & 1 & 3 & - & - & - & - & 4 & - & \multirow{3}{*}{11} \\
\hline & & Honorer & 3 & 4 & - & - & - & - & 7 & - & \\
\hline & & Sukarela & - & - & - & - & - & - & - & - & \\
\hline \multirow[t]{3}{*}{4.} & MTs Pekkabata & PNS & 1 & 1 & - & - & - & - & 2 & - & \multirow{3}{*}{15} \\
\hline & & Honorer & 5 & 8 & - & 1 & - & - & 12 & - & \\
\hline & & Sukarela & - & - & - & - & - & - & - & - & \\
\hline \multicolumn{3}{|c|}{ Jumlah } & 39 & 31 & - & 1 & - & - & 69 & - & 70 \\
\hline
\end{tabular}

Sumber Data: Kantor Kementerian Agama Kab. Pinrang Kasi Mapenda Th. 2012 
Keadaan Siswa Madrasah Tsanawiyah di Kecamatan Duampanua Kabupaten Pinrang

Siswa Madrasah Tsanawiyah di Kec. Duampanua Kab. Pinrang mengalami fluktuasi dalam jumlah peminatnya. Walaupun di tengah banyaknya sekolah menengah pertama (SMP) baik negeri maupun swasta di Kecamatan Duampanua, akan tetapi eksistensi madrasah tsanawiyah masih tinggi. Keadaan siswa madrasah tsanawiyah di Kecamatan Duampanua dapat dilihat pada tabel berikut:

Tabel 4. Keadaan Siswa Madrasah Tsanawiyah di Kecamatan Duampanua Tahun Pelajaran 2011-2012

\begin{tabular}{|c|l|c|c|c|}
\hline \multirow{2}{*}{ No. } & \multirow{2}{*}{ Satuan Madrasah } & \multicolumn{2}{|c|}{ Jenis Kelamin } & \multirow{2}{*}{ Jumlah } \\
\cline { 3 - 5 } & & Laki-Laki & Perempuan & \\
\hline 1. & MTs DDI Kaluppang & 52 & 38 & 90 \\
\hline 2. & MTs DDI Kaballangang & 75 & 36 & 111 \\
\hline 3. & MTs DDI Sokang & 12 & 38 & 50 \\
\hline 4. & MTs DDI Pekkabata & 49 & 48 & 97 \\
\hline & Jumlah & 188 & 160 & 348 \\
\hline
\end{tabular}

Sumber: Dokumen Arsip Madrasah Tsanawiyah Di Kec. Duampanua tahun 2012

\section{Tenaga Guru pada Madrasah Tsanawiyah Di Kecamatan Duampanua}

Peningkatan dan pengembangan tenaga kependidikan khususnya guru pada MTs. di kecamatan Duampanua didasarkan pada kebijakan pengembangan kemampuan profesional ketenagaan sebagai upaya untuk meningkatkan mutu dan kualitas pelayanan pendidikan. Peningkatan dan pengembangan dimaksud tentu saja diorientasikan pada peningkatan keahlian, wawasan, spirit ilmiah serta loyalitas pada tugas yang menjadi beban dan tanggung jawabnya sebagai seorang guru.

Tabel 5. Jumlah Guru Madrasah Tsanawiyah Di Kecamatan Duampanua Tahun Pelajaran 2011-2012

\begin{tabular}{|c|l|c|c|c|}
\hline \multirow{2}{*}{ No. } & \multirow{2}{*}{ Satuan Madrasah } & \multicolumn{2}{|c|}{ Jenis Kelamin } & \multirow{2}{*}{ Jumlah } \\
\cline { 3 - 4 } & & Laki-Laki & Perempuan & \\
\hline 1. & MTs DDI Kaluppang & 9 & 8 & 17 \\
\hline 2. & MTs DDI Kaballangang & 20 & 7 & 27 \\
\hline 3. & MTs DDI Sokang & 4 & 7 & 11 \\
\hline 4. & MTs DDI Pekkabata & 6 & 9 & 15 \\
\hline & JUMLAH & 39 & 31 & 70 \\
\hline
\end{tabular}

Sumber: Dokumen Arsip Kepala Seksi Mapenda Kemenag Kab. Pinrang th. 2012 


\section{Kemampuan dalam Pengelolaan Kelas}

Salah satu yang menjadi indikator tingkat profesionalisme seorang guru dalam pelaksanakan kegaiatan pembelajaran adalah kemampuannya di dalam mengelola kelas, sehingga kelasnya dapat memberikan peluang kepada dirinya untuk mengoptimalkan seluruh potensi kelas dalam rangka mencapai tujuan pembelajaran yang dilakukannya.

Tabel 6. Kemampuan dalam Pengelolaan Kelas Guru Pada Madrasah Tsanawiyah di Kecamatan Duampanua

\begin{tabular}{|c|l|c|c|}
\hline No & \multicolumn{1}{|c|}{ Alternatif Jawaban } & Frekuensi & Persentase (\%) \\
\hline 01 & Selalu & 45 & 52,2 \\
\hline 02 & Sering & 28 & 33,3 \\
\hline 03 & Jarang & 9 & 11 \\
\hline 04 & Tidak Pernah & 3 & 03,5 \\
\hline \multicolumn{2}{r|}{ Total } & 85 & 100 \\
\hline
\end{tabular}

Sumber: Data Primer diolah bulan Pebruari 2012

\section{Kemampuan dalam Penguasaan Materi Pembelajaran}

Indikator tingkat profesionalisme guru pada aspek kemampuan dalam penguasaan materi pelajaran, diukur dengan penggunaan instrument penelitian tentang tingkat pemahaman siswa terhadap materi yang disampaikan oleh seorang guru dalam proses pembelajaran yang dilakukannya. Hasil angket menunjukkan bahwa terdapat 53 orang responden atau sebesar 62,4 persen yang menjawab dengan menggunakan alternatif jawaban pertama yaitu selalu. Pernyataan ini selanjutnya dapat dipahami guru cukup baik dalam penguasaan materi pelajarannya, sehingga penjelasan terhadap materi yang disampaikan dapat dipahami dengan baik.

Tabel 7. Penguasaan Materi Pelajaran oleh Guru Madrasah Tsanawiyah di Kecamatan Duampanua

\begin{tabular}{|l|l|c|c|}
\hline No & \multicolumn{1}{|c|}{ Alternatif Jawaban } & Frekuensi & Persentase (\%) \\
\hline 01 & Selalu & 53 & 62,3 \\
\hline 02 & Sering & 22 & 25,9 \\
\hline 03 & Jarang & 9 & 10,6 \\
\hline 04 & Tidak Pernah & 1 & 01,2 \\
\hline \multicolumn{2}{r|}{ Total } & 85 & 100 \\
\hline
\end{tabular}

Sumber : Data Primer diolah bulan Pebruari 2012 
Tabel 8. Kesesuaian Materi Pelajaran dengan Latar Belakang Keilmuan Guru pada MTs. Di Kec. Duampanua

\begin{tabular}{|l|l|c|c|}
\hline No & \multicolumn{1}{|c|}{ Jenis Jawaban } & Frekuensi & Persentase (\%) \\
\hline 01 & Ya, Sesuai & 9 & $75 \%$ \\
\hline 02 & Tidak Sesuai & 3 & $25 \%$ \\
\hline \multicolumn{2}{|c|}{ Jumlah Total } & 12 & $100 \%$ \\
\hline
\end{tabular}

Sumber : Data Primer Pebruari 2012

\section{Kemampuan Guru dalam Penerapan Metode Pembelajaran}

Tabel 9. Kemampuan Guru Madrasah Tsanawiyah di Kecamatan Duampanua dalam Menerapkan Beberapa Metode Mengajar Bervariasi

\begin{tabular}{|l|l|c|c|}
\hline No & \multicolumn{1}{|c|}{ Alternatif Jawaban } & Frekuensi & Persentase (\%) \\
\hline 01 & Selalu & 48 & 56,4 \\
\hline 02 & Sering & 29 & 34,1 \\
\hline 03 & Jarang & 6 & 07,1 \\
\hline 04 & Tidak Pernah & 2 & 02,4 \\
\hline \multicolumn{2}{r|}{ Total } & 85 & 100 \\
\hline
\end{tabular}

Sumber : Data Primer diolah bulan Pebruari 2012

Tabel 10. Kemampuan Guru Membangkitkan Semangat Belajar Siswa

\begin{tabular}{|c|l|c|c|}
\hline No & \multicolumn{1}{|c|}{ Alternatif Jawaban } & Frekuensi & Persentase (\%) \\
\hline 01 & Selalu & 14 & 16,5 \\
\hline 02 & Sering & 16 & 18,8 \\
\hline 03 & Jarang & 20 & 23,5 \\
\hline 04 & Tidak Pernah & 35 & 41,2 \\
\hline \multicolumn{2}{|c|}{ Total } & 85 & 100 \\
\hline
\end{tabular}

Sumber : Data Primer diolah bulan Pebruari 2012

Tabel 11. Kemampuan Guru dalam Menyesuaikan Metode Mengajar

\begin{tabular}{|l|l|c|c|}
\hline No & \multicolumn{1}{|c|}{ Alternatif Jawaban } & Frekuensi & Persentase (\%) \\
\hline 01 & Selalu & 54 & 63,5 \\
\hline 02 & Sering & 24 & 28,2 \\
\hline
\end{tabular}




\begin{tabular}{|c|l|c|c|}
\hline 03 & Jarang & 5 & 05,9 \\
\hline 04 & Tidak Pernah & 2 & 02,4 \\
\hline Total & 85 & 100 \\
\hline
\end{tabular}

Sumber : Data Primer diolah bulan Pebruari 2012

\section{Kemampuan dalam Penggunaan Media Belajar/Alat Pembelajaran}

Profesionalisme guru dengan indikator kemampuan dalam penggunaan media atau alat pembelajaran dapat diungkapkan dengan menggunakan pengukuran instrumen-instrumen penelitian.

Instrumen penelitian tentang penggunaan alat/media pembelajaran dalam penyajian materi pelajaran. Penggunaan jawaban pertama yaitu selalu mendapat respon sebanyak 44 orang atau sebesar 51,8 persen dan 30 orang yang menjawab sering atau sebesar 35,3 persen. Sementara sebanyak 7 responden atau sebesar 08,2 persen yang menyatakan guru jarang menggunakan media dalam menjelaskan materi pelajaran dan 4 orang atau sebesar 04,7 persen yang menyatakan tidak pernah menggunakan media/alat pembelajaran.

Tabel 12. Kemampuan Menggunakan Alat/Media Pembelajaran oleh Guru pada Madrasah Tsanawiyah di Kecamatan Duampanua

\begin{tabular}{|c|c|c|c|}
\hline No & Alternatif Jawaban & Frekuensi & Persentase (\%) \\
\hline 01 & Selalu & 51 & 59,4 \\
\hline 02 & Sering & 26 & 30,6 \\
\hline 03 & Jarang & 5 & 05,5 \\
\hline 04 & Tidak Pernah & 3 & 03,5 \\
\hline & Total & 85 & 100 \\
\hline
\end{tabular}

Sumber : Data Primer diolah bulan Pebruari 2012

\section{Kemampuan dalam Melakukan Evaluasi Pembelajaran}

Untuk mengetahui tingkat keberhasilan kegiatan pembelajaran yang telah dilakukan oleh seorang guru dan benar-benar telah tercapai, baik yang terkait dengan tujuan, aktivitas pembelajaran, prosedur kerja yang dilakukan, mobilisasi sumber daya yang dimiliki, elemen-elemen pendukung kegiatan pembelajaran. Kesemuanya membutuhkan proses evaluasi untuk dapat menjawabnya. Karena itu, proses evaluasi memiliki kedudukan yang sama pentingnya dengan indikator-indikator pencapaian tujuan pembelajaran lainnya atau merupakan bagian integral yang tidak terpisahkan dengan proses dari kegiatan pembelajaran secara keseluruhan. 
Tabel 13. Kemampuan Dalam Pelaksanaan Evaluasi Pembelajaran oleh Guru Pada Madrasah Tsanawiyah di Kecamatan Duampanua

\begin{tabular}{|c|l|c|c|}
\hline No & \multicolumn{1}{|c|}{ Alternatif Jawaban } & Frekuensi & Persentase (\%) \\
\hline 01 & Selalu & 49 & 57,6 \\
\hline 02 & Sering & 29 & 34,1 \\
\hline 03 & Jarang & 6 & 07,1 \\
\hline 04 & Tidak Pernah & 1 & 01,2 \\
\hline \multicolumn{2}{|c|}{ Total } & 85 & 100 \\
\hline
\end{tabular}

Sumber : Data Primer diolah bulan Pebruari 2012

\section{Tingkat Pencapaian Prestasi Siswa Madrasah Tsanawiyah di Kecamatan Duampanua}

Peningkatan mutu pendidikan merupakan bahagian dari sistem pendidikan, baik yang berkaitan dengan sistem pengelolaan maupun dari aspek proses penyelenggaraan pendidikan itu sendiri. Pada hakekatnya, usaha-usaha yang dilakukan diarahkan secara efektif dan efesien untuk mencapai tujuan pendidikan, yaitu terjadinya peningkatan atau adanya nilai tambah dari faktor-faktor input agar menghasilkan keluaran yang memiliki mutu tinggi.

Pengukuran nilai rata-rata kelas diambil dari buku legger yang ada pada madrasah Tsanawiyah di kecamatan Duampanua. Pengambilan nilai rata-rata ditetapkan sebanyak 52 orang siswa, yaitu kelas VII sebanyak 18 orang siswa, kelas VIII sebanyak 17 orang siswa, dan kelas IX sebanyak 17 orang siswa.

Untuk mengetahui secara jelas tingkat prestasi belajar siswa pada kelas VII, kelas VIII dan kelas IX, dapat diperhatikan dalam beberapa tabel di bawah ini:

Tabel 14. Perbandingan Nilai Rata-Rata Prestasi Belajar Siswa Kelas VII dengan VIII Pada Siswa Yang Sama

\begin{tabular}{|c|c|c|c|c|}
\hline \multirow[t]{2}{*}{ No. } & \multirow[t]{2}{*}{ Nama Siswa } & \multicolumn{2}{|c|}{$\begin{array}{l}\text { Nilai Rata- } \\
\text { Rata Kelas }\end{array}$} & \multirow[t]{2}{*}{ Keterangan } \\
\hline & & VII & VIII & \\
\hline 1. & A. Asni Ramadhani & 7,2 & 7,5 & Bidang studi yang dijadikan \\
\hline 2. & A. Hartina & 7,0 & 7,4 & sebagai ukuran adalah semua \\
\hline 3. & Sukmawati & 7,9 & 8,5 & bidang studi pada tingkatan \\
\hline 4. & Nunung Anggreni & 7,4 & 7,5 & yang sama, seperti yang \\
\hline 5. & Sri Hastuti & 7,3 & 7,6 & termuat di dalam kurikulum \\
\hline 6. & Hasnah & 7,5 & 7,8 & tingkat Madrasah Tsanawiyah. \\
\hline 7. & Nur Fitria & 7,2 & 7,7 & \\
\hline 8. & Prawandhani & 7,9 & 7,8 & \\
\hline 9. & St. Zarkiah & 7,2 & 8,6 & \\
\hline
\end{tabular}




\begin{tabular}{|c|l|l|l|l|}
\hline 10. & Nirmalasari & 8,2 & 7,6 & \\
11. & Sri Putri Bulqis & 7,9 & 8,3 & \\
12. & Kamariah & 7,0 & 8,4 & \\
13. & Abd. Rahim & 6,5 & 7,5 & \\
14. & Kamaruddin & 7,4 & 7,9 & \\
15. & Sahabuddin & 7,1 & 7,3 & \\
16. & Iwan Setiawan & 6,9 & 7,5 & \\
17. & Muh. Ridwan & 6,8 & 7,3 & \\
18. & Burhanuddin & & & \\
\hline & Rata-Rata Kelas & 7,3 & 7,8 & \\
\hline
\end{tabular}

Sumber: Dokumen Madrasah Tsanawiyah di kecamatan Duampanua Tahun 2012.

Tabel 15. Perbandingan Nilai Rata-Rata Prestasi Belajar Siswa Kelas VIII Dengan IX Pada Siswa Yang Sama

\begin{tabular}{|c|c|c|c|c|}
\hline \multirow[t]{2}{*}{ No } & \multirow[t]{2}{*}{ Nama Siswa } & \multicolumn{2}{|c|}{$\begin{array}{l}\text { Nilai Rata- } \\
\text { Rata Kelas }\end{array}$} & \multirow[t]{2}{*}{ Bidang Studi } \\
\hline & & VIII & IX & \\
\hline 1. & Nur Syamsiar & 7,7 & 8,5 & \multirow{17}{*}{$\begin{array}{l}\text { Bidang studi yang dijadikan } \\
\text { sebagai ukuran adalah semua } \\
\text { bidang studi pada tingkatan } \\
\text { yang sama, seperti yang } \\
\text { termuat di dalam kurikulum } \\
\text { tingkat Madrasah Tsanawiyah. }\end{array}$} \\
\hline 2. & Rahmatani & 7,4 & 8,4 & \\
\hline 3. & Sukmaria & 8,2 & 8,5 & \\
\hline 4. & Kasmawati & 7,7 & 8,2 & \\
\hline 5. & Nur Aeni & 7,9 & 8,0 & \\
\hline 6. & Nismawati & 8,2 & 8,3 & \\
\hline 7. & Nur Annisa & 8,2 & 8,2 & \\
\hline 8. & Nur Hikmah & 7,3 & 7,8 & \\
\hline 9. & Nur Saba & 7,1 & 8,7 & \\
\hline 10. & Nurmiati & 7,5 & 7,9 & \\
\hline 11. & Mardiana & 7,4 & 7,9 & \\
\hline 12. & Sri Wahyuni & 7,3 & 7,6 & \\
\hline 13. & Muh. Ikbal & 6,8 & 7,7 & \\
\hline 14. & Muhammad Nur & 7,1 & 7,9 & \\
\hline 15. & Taufiq & 7,5 & 7,8 & \\
\hline 16. & Irwan Cahyadi & 7,9 & 6,9 & \\
\hline 17. & Irfan Affandi & 7,8 & 7,9 & \\
\hline & Rata-Rata Kelas & 7,6 & 8,0 & \\
\hline
\end{tabular}

Sumber: Dokumen Madrasah Tsanawiyah di Kecamatan Duampanua Tahun 2012.

\section{Hubungan Profesionalisme dengan Pencapaian Prestasi Belajar Siswa pada Madrasah Tsanawiyah}

Membahas tentang profesionalitas guru, merupakan perhatian utama dari dunia pendidikan. Sebab suatu adigium yang mengatakan bahwa kalau wibawa hutan dengan singanya, wibawa lembaga pendidikan tinggi dengan guru besarnya, maka sekolah/madrasah dengan guru-gurunya.

Karena itu, di awal pembahasan ini telah diasumsikan, bahwa guru yang profesional tentu akan menghasilkan peserta didik yang berkualitas, selanjutnya kaitannya 
dengan guru profesional dengan lembaga maka lembaga pendidikan akan semakin hidup, karena daya tarik yang dibawa oleh guru tersebut menjadi pemikat bagi peserta didik atau orang tuanya, dan yang lebih penting lagi adalah bahwa guru yang profesional akan mampu mengelola kelas secara baik, sehingga proses belajar mengajar dapat berjalan lancar.

Tabel 21. Alasan Siswa Masuk pada Madrasah Tsanawiyah di Kecamatan Duampanua

\begin{tabular}{|c|l|c|c|}
\hline No & \multicolumn{1}{|c|}{ Jenis Jawaban } & Frekuensi & Persentase (\%) \\
\hline 01 & Keinginan Sendiri & 19 & 36,54 \\
\hline 02 & Keinginan Orang Tua & 27 & 51,92 \\
\hline 03 & Ikut Teman & 6 & 11,54 \\
\hline 04 & Tidak ada Alasan & 0 & 0 \\
\hline & Total & 52 & 100 \\
\hline
\end{tabular}

Data Primer diolah bulan Pebruari 2012

Tabel 22. Tingkat Profesionalitas Guru pada Madrasah Tsanawiyah di Kecamatan Duampanua

\begin{tabular}{|c|l|c|c|}
\hline No & \multicolumn{1}{|c|}{ Jenis Jawaban } & Frekuensi & Persentase (\%) \\
\hline 01 & Tinggi Sekali & 3 & 04,16 \\
\hline 02 & Tinggi & 46 & 63,88 \\
\hline 03 & Sedang & 21 & 29,16 \\
\hline 04 & Rendah Total & 2 & 02,77 \\
\hline \multicolumn{2}{|c|}{} & 72 & 100 \\
\hline
\end{tabular}

Data Primer diolah bulan Pebruari 2012

\section{SIMPULAN}

Berdasarkan uraian pada beberapa pokok bahasan tentang profesionalisme guru dalam kaitannya dengan peningkatan prestasi belajar siswa pada Madrasah Tsanawiyah di Kecamatan Duampanua Kabupaten Pinrang sebagai berikut:

1. Profesionalisme guru pada Madrasah Tsanawiyah di Kecamatan Duampanua cukup memadai baik dari aspek kualitas maupun kuantitasnya. Data dokumen arsip menunjukkan bahwa kualifikasi pendidkan guru yang ada sebanyak 69 orang berkualifikasi sarjana atau sebesar 98,57 persen dari populasi sebanyak 70 orang. 1 
orang diantaranya atau sebesar 01,42 persen adalah lulusan Diploma Dua dan sementara dalam proses penyelesaian kesarjanaannya.

2. Prestasi belajar siswa pada Madrasah Tsanawiyah di Kecamatan Duampanua Kabupaten Pinrang tergolong dalam kategori yang Tinggi. Hal ini dibuktikan dengan data-data dokumen penelitian yang menunjukkan bahwa nilai rata-rata kelas VII, VIII dan IX masing-masing tergolong tinggi. Peningkatan prestasi belajar siswa tersebut, dapat dibandingkan dengan perolehan nilai rata-rata pada VIII dan IX pada siswa yang sama, dan perbandingan antara kelas VII dengan Kelas VIII pada siswa yang sama pula. Perbandingan tersebut didapatkan perolehan peningkatan prestasi belajar siswa masing-masing rata-rata sebesar 0,5 poin dan 0,42 poin.

3. Tingkat profesionalisme guru terhadap peningkatan prestasi belajar siswa pada Madrasah Tsanawiyah di Kecamatan Duampanua Kabupaten Pinrang , diukur dengan kemampuan guru dalam beberapa aspek, yaitu; kemampuan dalam pengelolaan kelas, kemampuan dalam penguasaan materi, kemampuan dalam penerapan matode yang sesuai dengan materi pelajaran, kemampuan dalam menggunakan alat/media pembelajaran, kemampuan dalam melaksanakan evaluasi pembelajaran. Kelima aspek tersebut masing-masing masuk dalam kategori tinggi sebesar 78,66 persen. Hasil ini memberikan informasi bahwa terdapat indikator-indikator lain yang mempunyai pengaruh terhadap tingkat profesionalisme guru dalam meningkatkan prestasi belajar siswa pada Madrasah Tsanawiyah di Kecamatan Duampanua Kabupaten Pinrang.

Berdasarkan pada kesimpulan di atas, dapat dinyatakan bahwa tingkat profesionalisme guru dalam meningkatkan prestasi belajar siswa mempunyai pengaruh yang kuat. Hal ini terbukti berdasarkan pada hasil pengolahan data yang masing-masing indikator memperoleh penilaian yang tinggi, sekaligus menjadi indikator utama dalam memmberikan penilaian bahwa terdapat pengaruh yang signifikan antara tingkat profesionalisme guru dengan tingkat prestasi belajar siswa pada Madrasah Tsanawiyah di Kecamatan Duampanua kabupaten Pinrang.

\section{IMPLIKASI PENELITIAN}

Berdasarkan hasil penelitian, dan kesimpulan yang diambil, maka beberapa implikasi dapat dikemukakan sebagai berikut:

1. Kepala Madrasah Tsanawiyah yang ada di Kecamatan Duampanua kabupaten Pinrang, diharapkan mampu untuk tetap mempertahankan capaian prestasi pengelolaan lembaga secara profesional, sehingga mutu luaran madrasah mampu bersaing dengan luaran dari sekolah-sekolah yang sederajat lainnya.

2. Para guru agar senantiasa tetap meningkatkan profesionalismenya, sehingga pembinaan terhadap siswa dapat berlaku maksimal.

3. Kepada para siswa diharapkan agar lebih giat lagi didalam belajar, memiliki wawasan yang luas, mampu berkreasi dalam belajar dan tetap memiliki motivasi yang kuat dalam mengikuti materi pembelajaran. 
4. Kepada para peneliti selanjutnya, agar tetap memiliki motivasi untuk meneliti permasalahan yang sama dengan pendekatan-pendekatan yang lebih baik lagi. Sehingga dapat ditemukan berbagai alternatif lainnya dalam rangka untuk mencapai tujuan dari proses penyelenggaraan pendidikan diharapkan.

\section{CATATAN AKHIR:}

1. Departemen Pendidikan dan Kebudayaan, Undang-Undang Republik Indonesia Nomor 20 Tahun 2003 Tentang Sistem Pendidikan Nasional (Jakarta: 2003), Bab II Pasal 3.

2. Ahmad Tafsir, Ilmu Pendidikan Dalam Perspektif Islam (Cet. III; Bandung: Remaja Rosda Karya, 1991), h. 107.

3. Abuddin Nata, Paradigma Pendidikan Islam Kapita Selekta Pendidikan Islam (Cet. I; Jakarta: Gramedia, 2001), h. 136.

4. Departemen Pendidikan dan Kebudayaan, Kamus Besar Indonesia (Cet. IX Jakarta: Balai Pustaka, 1997), h. 657.

5. Ibid, h. 15.

6. Ibid., h. 26.

7. Muhibbin Syah, Psikologi Pendidikan Dengan Pendekatan Baru (Cet. IX; Bandung: PT. Remaja Rosdakarya Offset, 2004), h. 136.

8. Carter V. Good, Dictionary of Education, Third Edition, (New York : McGraw-Hill ; Book Company, 1973), h. 4. Bandingkan dengan Burhanuddin, Analsis Administrasi ..., op.cit., h. 39.

9. Wahyu, dan Muhammad Masduki, Petunjuk Praktis Membuat Skripsi (Surabaya-Indonesia: Usaha Nasional, 1987), h. 50.

10. Sumber Data: Dokumen Arsip Kurikulum Tingkat Satuan Pendidikan pada Madrasah Tsanawiyah di kecamatan Duampanua kabupaten Pinrang Tahun 2012.

\section{DAFTAR PUSTAKA}

Ahmad Tafsir, llmu Pendidikan Dalam Perspektif Islam. Cet. I; Bandung: Remaja Rosdakarya, 1992.

Ali, Muhammad, Pengembangan Kurikulum di Sekolah. Cet. II; Bandung: Sinar Baru, 1989.

Al-Qur'an Al-Karim

Arifin, M., llmu Pendidikan Islam Suatu Tinjauan Teoritis dan Praktis Berdasarkan Pendekatan Interdisipliner. Cet. I; Jakarta: Bumi Aksara, 1991.

Ashraf, AH, The New Horison. Diterjemahkan oleh Soni Siregar dengan judul Horison Baru Pendldikan Islam, Jakarta: Pustaka Firdaus, 1993.

Azra, Azyumardi, Pendldikan Islam Tradisi dan Modernitas Menuju Millenium Baru. Jakarta: Logos Wacana llmu, 1999.

Burhanuddin, Analisis Administrasi Manajemen dan Kepemimpinan Pendidikan. Cet. I; Jakarta: Bumi Aksara, 1994.

Carter, V. Good, Dictionary of Education. Third Edition; New York: McGraw-Hill Book Company, 1973.

Daradjat, Zakiah, Ilmu Pendidikan Islam. Cet. 2; Jakarta: Bumi Aksara, 1992.

Departemen Agama RI, Himpunan Peraturan dan Perundang-undangan Tentang Pendidikan Nasional (Perguruan Agama Islam). Jakarta: Ditjen Bimbaga Islam, 2000.

Departemen Agama RI, Kendali Mutu Pendidikan Agama Islam. Jakarta: Direktorat Jenderal Pembinaan Kelembagaan Agama Islam, 2001. 
Departemen Agama RI, Metodologi Pendidikan Agama Islam. Jakarta: Ditjen Bimbaga Islam, 2001.

Departemen Agama RI., Al-Qur'an dan Terjemahnya. Edisi Baru; Bandung: Lubuk Agung, 1995.

Departemen Pendidikan dan Kebudayaan RI, Manajemen Peningkatan Mutu Berbasis Sekolah; Buku I Konsep dan Pelaksanaan. Jakarta: Direktorat Jenderal Pendidikan Dasar dan Menengah/Direktorat Sekolah Lanjutan Tingkat Pertama, 2001.

Departemen Pendidikan dan Kebudayaan RI, Undang-Undang Republik Indonesia tentang Sistem Pendidikan Nasional (UU RI. No. 20 Th. 2003). Jakarta: BP. Cipta Jaya, 2003.

Departemen Pendidikan dan Kebudayaan RI., Kamus Besar Bahasa Indonesia. Jakarta: Balai Pustaka, 1995.

Fadjar, A. Malik, Flatform Reformasi Pendidikan dan Pengembangan SDM. Cet. II; Jakarta: Logos, 2001.

Fadjar, A. Malik, Visi Pembaharuan Pendidikan Islam. Cet. 1; Jakarta: Lembaga Pengembangan Pendidikan dan Penyusunan Naskah Indonesia (LP3NI) 1998.

Fattah, Nanang, Landasan Manajemen Pendidikan. Cet. Ill; Jakarta: Remadja Rosdakarya, 2000.

Handoko, Hani, Manajemen Personalia dan Sumber Daya Manusia. Edisi 2; Yogyakarta: BPFE, 1994.

Harold Koontz, Cytil O'Donnel, Heinz Wheichrich, Management, Eight Edition; diterjemahkan oleh Alfonso Sirait dengan judul Manajemen. Jilid I; Cet. VIII; Jakarta: Erlangga, 1996.

Hasibuan, Melayu, Manajemen Oasar Pengertian dan Masalah. Jakarta: Gunung Agung, 1985.

Isa, Muhammad Kamal, DR., Khasaish Madrasatin Nubuwah, diterjemahkan oleh Chairul Halim dengan judul Manajemen Pendidikan Islam. Cet. I; Jakarta: Fikahati Aneska, 1994.

Madjid, Nurcholis, Bilik-bilikPesantren. Cet. I; Jakarta : Yayasan Paramadina, 1997.

Maksum, Madrasah Sejarah dan Perkembangannya. Cet. I; Jakarta: Logos Wacana Hmu, 1994.

Mappanganro, Implementasi Pendidikan Islam di Sekolah. Ujungpandang: Al-Kalam, 1996.

Mardalis, Metode Peneliiian Suatu Pendekatan Proposal. Cet. Ill; Jakarta: Bumi Aksara, 1993.

Mustafa, Abdullah, dkk., Sejarah Pendidikan Islam di Indonesia. Bandung: Pustaka Setia, 1997.

Nata, Abdullah, Paradigma Pendidikan Islam Kapita Selekta Pendidikan Islam. Cet. I; Jakarta: Gramedia, 2001.

Nata, Abdullah, Sejarah Pertumbuhan dan Perkembangan Lembaga Pendidikan Islam di Indonesia. Jakarta: Bulan Bintang, 1976.

Ndraha, Taliziduhu, Pengantar Teori Pengembangan Sumber Daya Manusia. Cet. I; Jakarta: Rineka Cipta, 1999.

Pidarta, Made, Manajemen Pendidikan Indonesia. Cet. I; Jakarta: Bumi Aksara, 1988.

Rahim, Husni, Arah Baru Pendidikan Islam di Indonesia. Cet. I; Jakarta: Logos Wacana Ilmu, 2001.

Ridha", Muhammad Rasyid, Al-Tarbiyah Al-Islamiyah Wa Al-Tarikh Islamy "Al-Manar". BeirutLibanon: Daral-Fikr, 1314 H/1935 M.

Steenbrink, Karel A., Pesantren, Madrasah, Sekolah, Pendidikan Islam Dalam Kurun Modern. Cet. II; Jakarta: LP3ES, 1988.

Sukmadinata, Nana Syaodih, Pengembangan Kurikulum Teori dan Praktek. Cet. I; Bandung: RemadjaRosdakarya, 1999.

Syah, Muhibbin, Psikologi Belajar. Cet. V; Jakarta: PT. Raja Gra findo Persada, 2006.

Syalabi, Ahmad, Al-Tarbiyah Al-Islamiyah, Nuzumubah, Falsafatuha, Thariquha. Cairo: Maktabah Al-Naqdah Al-Misyriyah, 1987.

Tabana, Imam Badwy, Ilrya 'UlumuddmLil Imam al-Ghazali. Jilid I; Saudi Arabiyah: Dar al-Ihya al-Kutub al-Arabiyah, t.th.

Usman, M. Basyiruddin, Metodologi Pembelajaran Agama Islam. Cet. III; Jakarta: Ciputat Press, 2005. 
Uwes, Sanusi, Manajemen Pengembangan Mutu Dosen. Cet. I; Jakarta: Logos Wacana limu, 1999. Yunus, Mahmud, Sejarah Pendidikan Islam di Indonesia. Cet. II; Jakarta: Up., 1979.

Zuhairini, dkk., Sejarah Pendidikan Islam di Indonesia. Cet. II; Jakarta: Bumi Aksara, 1995. 